\title{
Research on the Dynamic Soil Moisture Contents using Hydrus-3D model
}

\author{
Zhan Liang $^{1, \text { a }}$, Jing Zhang ${ }^{1 *},{ }^{b}$ and Binbin Guo ${ }^{1, c}$ \\ ${ }^{1}$ Key Laboratory of 3D Information Acquisition and Application of Ministry of Education, \\ Capital Normal University, Beijing 100048, China ) \\ ${ }^{*}$ Corresponding author \\ ayqyliangzhan@163.com, ㄹ maggie2008zj@yahoo.com, guobinbinbin@126.com
}

Keywords: Hydrus-3D, soil moisture, leakage, deficit, vegetation

Abstract. Soil moisture, as an important existing form of water resources, has close ties with the field of agriculture, hydrology and environment. Hydrus model is an important means to simulate the complex soil moisture movement. In this paper, Hydrus-3D model was used to simulate soil moisture, the model was validated through the comparison of simulated and measured values, and the deep soil moisture leakage of study soil volume was obtained by simulating soil moisture. Then, the soil moisture movement law of Myakka fine sand was analyzed. In the end, concerning the study area under shallow water table environment, the vegetation response to soil moisture content deficit was discussed using the water balance principle.

\section{Introduction}

Soil moisture is the main source of plant water uptake (except hydroponic plants), soil moisture has close exchange relationships with the atmosphere, surface water, groundwater, plants and other elements [1].Therefore, research on the mechanism of soil water movement is very important in many aspects.

Hydrus-3D (the Microsoft Windows-based finite element analysis software package for simulating water, heat, and solute transport in variably saturated porous media) model [2], based on Richards equation, is a hydraulic model developed by the US Salinity Laboratory and International Ground Water Modeling Center (IGWMC). Richards's equation is the theoretical basis of Hydrus-3D. Currently there are 3 different versions of Hydrus model (Hydrus-1D, Hydrus-2D and Hydrus-3D) [3].

\section{Research progress}

\section{Foreign research progress}

Hydrus model has been widely used abroad. In 2004, Schlegel et al (2004) simulated species and spacing effects on root zone water dynamics using Hydrus-2D in an Amazonian agroforestry system [4]; Šimůnek et al (2005) used Hydrus-1D to study multicomponent geochemical transport modelling [5]; Phillips (2006) used Hydrus-2D to simulate water and chemical transport in large undisturbed soil cores [6]; Hilten et al (2008) simulated the storm water runoff from green roofs with Hydrus-1D [7]; Doltra et al (2009) modeled nitrogen leaching from a fertigated crop rotation in a Mediterranean climate using the EU-Rotate_N and Hydrus-2D models [8]; Kandelous et al (2010) simulated the water movement in a subsurface drip irrigation system under field and laboratory conditions with Hydrus-2D [9]; Tafteh et al (2012) used Hydrus-1D to simulate water and nitrate leaching from continuous and alternate furrow irrigated rapeseed and maize fields [10].

\section{Local research progress}

The Hydrus model has been widely used in China, as well. Hu et al (2006) used Hydrus-1D to study surface soil saturated hydraulic conductivity of the spatial variation effect on farmland water leakage [11]; Zhou et al (2007) comparison of APRI and Hydrus-2D models to simulate soil water 
dynamics in a vineyard under alternate partial root zone drip irrigation [12]; Hao et al (2008) simulated the nitrogen migration under different irrigation applied situation of Hetao irrigation area with Hydrus-1D [13]; Zhang et al (2009) used Hydrus-1D for the observations of long term air entrapment affecting runoff and water table [14]; Li et al (2011) used Hydrus-3D to simulate and study the Soil Moisture Contents of Two Typical Natural Vegetation Communities on the Sanjiang Plain comparatively [1]; Wang et al (2013) used Hydrus-1D to study the effect of vegetation on soil water retention and storage in a semi-arid alpine forest catchment [15].

\section{Research progress of analysis}

From the applications of the Hydrus model mentioned above, they mainly focus on Hydrus-1D model and Hydrus-2D model around the world. The application fields were mainly focus on the simulation of soil moisture and soil solute transport. The applications of Hydrus-3D model are limited.

\section{Research content}

\section{Study area}

The study was located in the sub basin of Long Flat Creek, a tributary of the Alafia River, adjacent to the Tampa Bay regional reservoir in Lithia, Florida. The vegetation varied from ungrazed Bahia grass in the upland area, to alluvial wetland forest composed of slash pine/ hardwood trees near the stream, the area between the two is characterized as a mixed zone, Because of these reasons the area was selected to illustrate the relationship between the soil moisture and vegetation [16].

The soil in the study area is primarily Myakka fine sand (of marine origins) with high permeability $\left(10^{-1}\right.$ to $\left.10 \mathrm{~m} / \mathrm{d}\right)$ in the surface and subsurface layers. Fig 1 shows the soil stratigraphy, the soil was primarily sand with the presence of a clay layer at a depth, which varied from $4 \mathrm{~m}$ below land surface in the upland regions to about $2.5 \mathrm{~m}$ below land surface near the stream region. The lower confining layer can be assumed as an impermeable layer.

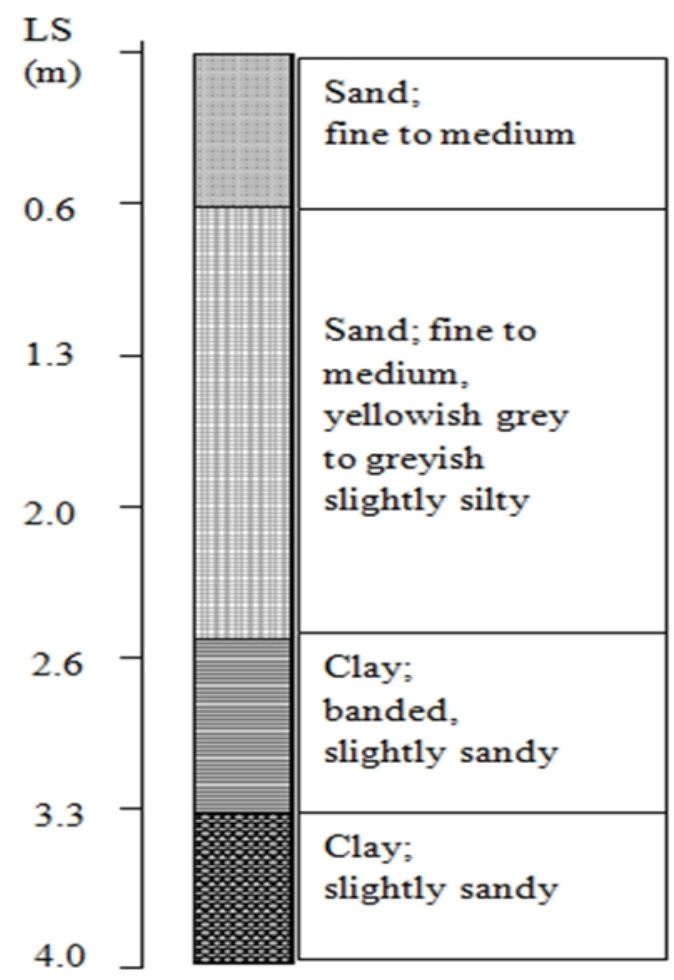

Figure 1 Soil Stratigraphy [16]

Field observations of water content obtained from the soil moisture sensors show that the soil profile is far from homogenous even at a vertical scale of $1.5 \mathrm{~m}$. Hence, with the purpose of making the model representative of actual soil column in the study area, the simulated soil column was set up 
with eight different soil layers $(10,20,30,50,70,90,110$, and $150 \mathrm{~cm}$ from the land surface), each corresponding to a soil moisture sensor[14].

\section{Methodology}

Soil is assumed to be homogeneous, isotropic, and does not consider the impact of the air, temperature and the affection of soil water hysteresis on soil water movement.

Soil water movement is described by Richards's equation in Hydrus-3D model:

$$
\frac{\partial \theta}{\partial t}=\frac{\partial}{\partial x}\left[K(\theta) \frac{\partial \varphi_{m}}{\partial x}\right]+\frac{\partial}{\partial y}\left[K(\theta) \frac{\partial \varphi_{m}}{\partial y}\right]+\frac{\partial}{\partial z}\left[K(\theta)\left(\frac{\partial \varphi_{m}}{\partial z}+1\right)\right]
$$

Where

$\varphi_{m}$ is the pressure head $(\mathrm{cm}) ;{ }^{K(\theta)}$ is the unsaturated hydraulic conductivity function $(\mathrm{cm} / \mathrm{min}) ; \theta$ is the volumetric water content $\left(\mathrm{cm}^{3} / \mathrm{cm}^{3}\right)$; $\mathrm{t}$ is the time $(\mathrm{min}) ; \mathrm{z}$ is the vertical coordinate $(\mathrm{L}), \mathrm{x}$ and $\mathrm{y}$ are the horizontal coordinates (L).

\section{Data preparation}

The meteorological data such as rainfall, evaporation and soil particle composition data was applied to the model to simulate the soil moisture. Meteorological data and the measured soil moisture content data were obtained by the field measurement, the data sources as shown in fig 2 .

\section{Simulation process}

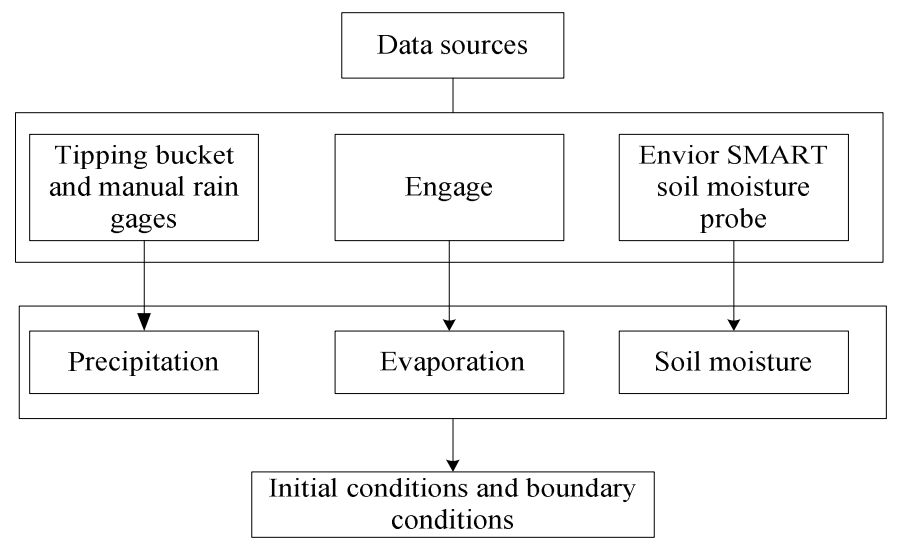

Figure 2 Data sources

The simulation process of soil moisture with Hydrus-3D is shown in fig 3.

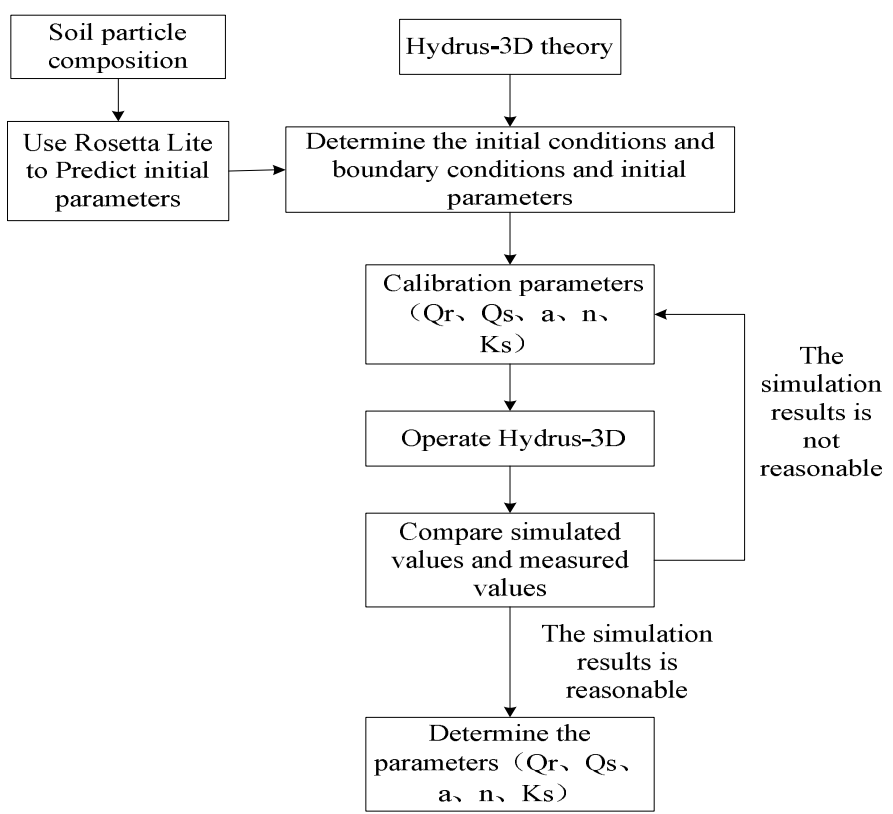

Figure 3 Simulation process 


\section{Result analysis}

Water balance principle was used in the analysis of the results. The value of water balance within a certain period of time reflects the soil moisture within a period of movement, as well as the influence of vegetation on soil moisture condition [17]. Fig 4 shows the analysis process.

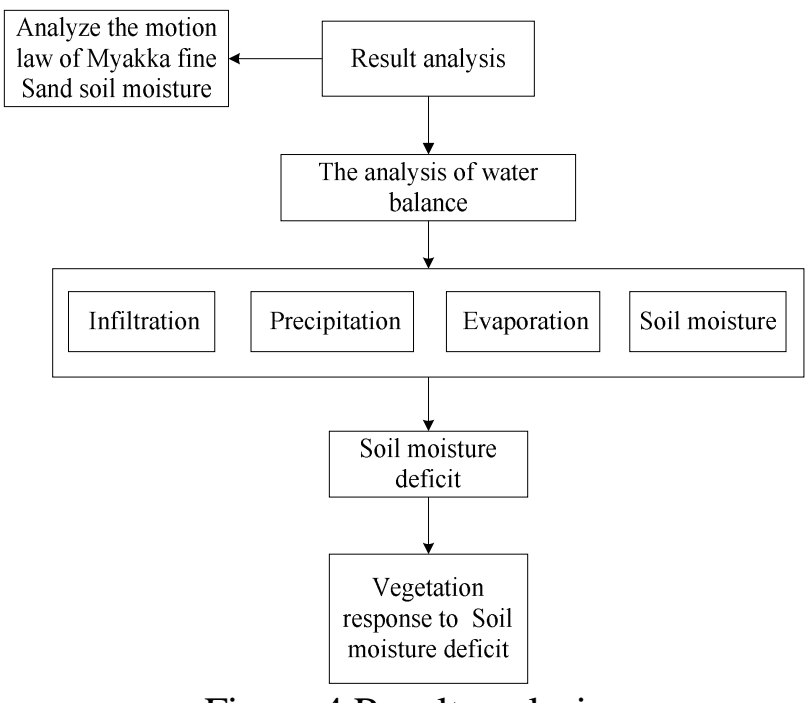

Figure 4 Result analysis

\section{Conclusion}

Myakka fine is the official soil of Florida. Some parts of Florida soil properties can be roughly understand through the analysis of the soil in the study area. By the research, useful information would be provided in protecting the vegetation of the study area. But this study did not consider the root water absorption and temperature on the influence of soil water movement. These factors should be fully considered in order to increase the reliability of the study on soil water movement law in the future.

\section{Acknowledgment}

This work was supported by national natural science foundation (41271004), Beijing nova program (2010b046).

\section{References}

[1] S.H. Li, D. M. Zhou, Z. Q. Luan, Y. Pan, C. C. Jiao, Numerical Simulation and Comparative Study of Soil Moisture Contents of Two Typical Natural Vegetation Communities on the Sanjiang Plain, J. Chinese Geographic Science. 21 (2011) 723-733.

[2] J. Šimůnek, M. T. van Genuchten, M. Šejna, Development and applications of the Hydrus and Stanmod software packages and related codes, J. Vadose Zone Journal. 7 (2008) 587-600.

[3] C. L. Wu, X. M. Mu, P. Gao, Soil water resources research progress and reviewed, J. Research of Soil and Water Conservation, 03 (2008) 255-257.

[4] P. Schlegel, B. Huwe, W. G. Teixeira, Modelling species and spacing effects on root zone water dynamics using Hydrus-2D in an Amazonian agroforestry system, J. Agroforestry Systems, 60 (2004) 277-289. 
[5] J. Šimůnek, D. Jacques, M. T. van Genuchten, D. Mallants, Multicomponent geochemical transport modeling using the Hydrus-1D computer software package, J. Awra Summer Specialty Conference. (2005) 1537-1547.

[6] I. R. Phillips, modeling water and chemical transport in large undisturbed soil cores using Hydrus-2D, J. Australian Journal of Soil Research. (2006) 27-34.

[7] R. N. H. Thomas. M. Lawrence, E. W. Tollner, Modeling storm water runoff from green roofs with Hydrus-1D, J. Journal of Hydrology. 358 (2008) 288-293.

[8] J. Doltra, P. Munoz, Simulation of nitrogen leaching from a fertigated crop rotation in a Mediterranean climate using the EU-Rotate_N and Hydrus-2D models, J. Agricultural Water Management, 97 (2010) 277-285

[9] M. M. Kandelous, J. Šimůnek, Numerical simulations of water movement in a subsurface drip irrigation system under field and laboratory conditions with Hydrus-2D, J. Agricultural Water Management. (2010)1070-1076

[10] A. Tafteh, A. R. Sepaskhah, Application of Hydrus-1D model for simulating water and nitrate leaching from continuous and alternate furrow irrigated rapeseed and maize fields, J. Agricultural Water Management. 113 (2012) 19-29.

[11] K. L. Hu, B. G. Li, Y. Chen, Surface soil saturated hydraulic conductivity of the spatial variation effect on farmland water leakage, N. Journal of hydraulic engineering. 37 (2006) 1217-1223.

[12]Q. Y. Zhou, S. Z. Kang, L. Zhang, F. S. Li, Comparison of APRI and Hydrus-2D models to simulate soil water dynamics in a vineyard under alternate partial root zone drip irrigation, J. Plant Soil 291 (2007) 211-223

[13]F. H. Hao, W. Sun, A. Y. Zeng P. Li, J.X. Zhang, Y. Yue, Simulated the nitrogen migration under different irrigation applied situation of Hetao irrigation area with Hydrus-1D, N. Acta Scientiae Circumstantiae. 28 (2008) 853-858.

[14] J. Zhang, N. Shah, M. A. Ross, Observations of long term air entrapment affecting runoff and water table, J. Int. J. Water., 5 (2009) 140-162.

[15] C. Wang, C.Y .Zhao, Z. Lin, Y. Wang, H. H. Peng, Effect of vegetation on soil water retention and storage in a semi-arid alpine forest catchment, J. J Arid Land. 5 (2013) 207-219.

[16] N. Shah, Vadose Zone Processes Affecting Water Table Fluctuations: Conceptualization And Modeling Considerations, D. University of South Florida. 2007.

[17] J. Jiang, Dynamics of soil moisture content and water balance studies in Nanxiaohegou Watershed forest land, D. Xi'an University of Technology. 2007. 